\title{
62, MODELO PARA ARMAR: NOVELA CALIDOSCOPIO
}

\author{
Por \\ JAIME ALAZRAKI \\ Harvard University
}

62, modelo para armar es la realización de un proyecto bosquejado por Morelli en el capítulo 62 de Rayuela. En la descripción de ese libro futuro "que se quedó en notas sueltas", Morelli explicaba que "al margen de las conductas sociales, podría sospecharse una interacción de otra naturaleza, un billar que algunos individuos suscitan o padecen, un drama sin Edipos, sin Rastignacs, sin Fedras, drama impersonal en la medida en que la conciencia y las pasiones de los personajes no se ven comprometidas más que a posteriori. Como si los niveles subliminales fueran los que atan y desatan el ovillo del grupo comprometido en el drama. Como si ciertos individuos incidieran sin proponérselo en la química profunda de los demás y viceversa, de modo que se operaran las más curiosas e inquietantes reacciones en cadena, fisiones y transmutaciones". ${ }^{1}$ Un párrafo más adelante, Morelli aclara que "si escribiera ese libro, las conductas estandard (incluso las más insólitas) serían inexplicables con el instrumental psicológico al uso. Los actores parecerían insanos o totalmente idiotas. No que se mostraran incapaces de los challenge and response corrientes: amor, celos, piedad y así sucesivamente, sino que en ellos algo que el homo sapiens guarda en lo subliminal se abriría penosamente un camino como si un tercer ojo parpadeara penosamente debajo del hueso frontal. Todo sería como una inquietud, un desasosiego, un desarraigo continuo, un territorio donde la causalidad psicológica cedería desconcertada, y esos fantoches se destrozarían o se amarían o se reconocerían sin sospechar demasiado que la vida trata de cambiar la clave en y a través y por ellos, que una tentativa apenas concebible nace en el hombre como en otro tiempo fueron naciendo la clave-razón, la clave-sentimiento, la clavepragmatismo. Que a cada sucesiva derrota hay un acercamiento a la mutación final, y que el hombre no es sino que busca ser, proyecta ser, manoteando entre palabras y conductas y alegría salpicada de sangre y otras retóricas como esta". ${ }^{2}$

1 Julio Cortázar, Rayuela (Buenos Aires: Sudamericana, 1963), pp. 416-417.

2 Rayuela, p. 418. 
El breve capítulo de Rayuela, además de anunciar y esbozar la novela que Cortázar publicará cinco años más tarde, anticipa algunos elementos específicos. El motivo de la ciudad, por ejemplo, como espacio que corporiza un mundo público y convencionalizado, un mundo que se nos impone no tanto por su verdad como por la dureza de su visibilidad. ¿Cómo integrar a sus límites 'deseos, simpatías, voluntades, convicciones irreductibles a toda razón y a toda descripción'? Es el tema ya planteado por Morelli desde sus notas: "Fuerzas habitantes-dice-, extranjeras, que avanzan en procura de su derecho de ciudad". Lo que es una metáfora en Rayuela deviene realidad literal en 62: la ciudad es un espacio físico al cual buscarán entrar esas fuerzas que mueven y gobiernan a sus personajes, la ciudad, entonces, como puerta, como validación y reconocimiento de lo otro.

Un segundo ejemplo de anticipo es la alusión en Rayuela a un territorio en el que "la vida trata de cambiar de clave". Pues bien, Hélène, personaje axial de 62 , en quien convergen todos los hilos de una posible clave de la novela vive en "la rue de la Clef". Aquí el procedimiento es de signo contrario: un detalle trivial en su literalidad adquiere el valor de una metáfora.

Pero aunque varias de las situaciones y conductas noveladas en 62 responden a una clave vampirista ${ }^{3}$ es difícil, y en el peor de los casos equivocado, concluir que 62 es una novela de vampiros. No solamente porque no es un historia de vampiros y no responde a la preceptiva de ese género, sino porque su complejidad y a mbigüedad lo rebasan. Ya Morelli advertía que los personajes de su proyectada novela "no se mostrarían incapaces de los challenge and response corrientes". ${ }^{4}$ Quería decir que no estarían sujetos a un código exclusivo. Aunque el código vampirista ayuda a explicar algunas de las situaciones y conductas de 62 , la novela airea preocupaciones y problemas que desbordan del modelo gótico. Cortázar no se propone un duelo con el miedo y el horror. Su desafío está más bien dirigido hacia algunos de los supuestos más sólid os de nuestra cultura: el tiempo, el espacio, y la psicología. De ese desafío, más que de la tradición de los nosferati, emerge lo más duradero de 62 . Cortázar ha dicho que "la noción del tiempo y del espacio como lo concibió el espíritu griego y tras él casi todo el Occidente, carece de sentido en el Vedanta. En cierto modo el hombre se equivocó al inventar el tiempo".5 62 se apoya en un tiempo que no es el histórico, en un espacio que no es el de la

\footnotetext{
${ }^{3}$ Para este aspecto de 62, véase el artículo de Ana María Hernández, "Vampires and Vampiresses: A Reading of 62 ", en The Final Island; The Fiction of Julio Cortázar, ed de Jaime Alazraki e Ivar Ivask (Norman: University of Oklahoma Press, 1978), pp. 109-114. Hernández define "el vampirismo como el tema central de la novela", p. 109.

4 Rayuela, p. 417.

${ }^{5}$ Luis Harss, Los nuestros (Buenos Aires: Sudamericana, 1968), p. 268.
} 
geometría, en psicologías que desorientarían a Freud. La construcción de 62 como tex to literario responde a esas coordenadas. El texto está armado desde esos agarraderos: un tiempo en el que se conjugan pasado y presente; un espacio en el que se sobreponen tres ciudades que son la misma ciudad: la ciudad; conductas inexplicables por la psicología al uso.

La primeras treinta páginas definen un ideograma que el resto del texto descifra o intenta descifrar. Aquí están dados todos los ingredientes que, como en una receta de cocina, el texto luego combina y mezcla. El narrador, Juan, está sentado en una mesa del restaurante Polidor. Todo ocurre como un acto ordinario y fortuito; nada lo es: el nombre del restaurante alude a John William Polidori, autor de la novela The Vampyre; el pedido del comensal gordo, un château saignant (un Chateaubriand poco asado) y que Juan traduce "un castillo sangriento", nos remite a los castillos, a las perversiones sexuales y a los excesos de sangre de Klara y Erszebet Báthory; la botella de vino Sylvaner que Juan pide recuerda de inmediato la patria de los vampiros, Transylvania; el libro, comprado antes de entrar en el restaurante, de Michel Butor, que por la aliteración de sus tres consonantes está claramente unido al nombre de Báthory y abierto, un segundo antes de que el comensal gordo pidiera su Chateaubriand, en una página en la que Butor habla del autor de Atala. En un instante fortuito y privilegiado todos estos elementos se aglutinan en la conciencia de Juan: "Imposible separar las partes, el sentimiento fragmentado del libro, la condesa, el restaurante Polidor, el castillo sangriento, quizá la botella de Sylvaner: quedó el cuajo fuera del tiempo, el privilegiado horror exasperante y delicioso de la constelación, la apertura a un salto que había que dar..." ".

La introducción presenta también algunos fragmentos aislados de la historia: personajes, lugares, escenas, situaciones, conversaciones y reflexiones comprensibles solamente en el contex to más amplio de toda la novela. Aquí están intercalados de la misma manera que los adarmes primeros entraban en ese instante en que un comensal pide "un château saignant". Disposición telescópica, pues, en que un hecho casual precipita las claves de una posible lectura de esa historia apenas aludida desde las piezas aisladas de un rompecabezas que la novela procederá a armar.

Un último detalle no sin significación para el modo cómo se construye la historia: en el restaurante, Juan se sienta en una mesa del fondo, "frente a un gran espejo que duplicaba precariamente la desteñida desolación de la sala" (p. 9). Esta primera referencia a un espejo, no menos trivial que el pedido del comensal gordo, y las sucesivas alusiones a otros espejos a lo largo del texto

6 Julio Cortázar, 62, modelo para armar (Buenos Aires: Sudamericana, 1968), pp. 21-22. Citas subsiguientes indicadas en el texto por el número de página de esta edición. 
apuntan al carácter especular o reflexivo de toda la novela, porque así como en la escena del restaurante los fragmentos de la historia están intercalados y confrontados con los fragmentos de una clave vampirista, la novela toda está armada como una galería de espejos o como un laberinto de ecos en que una voz, o una imagen o un hecho conlleva o desencadena otras. "Un espejo de espacio y un espejo de tiempo"-dice Juan frente al espejo del Polidor"habían coincidido en un punto de insoportable y fugacísima realidad antes de dejarme otra vez a solas con tanta inteligencia, con tanto antes y atrás y adelante y después" (p. 30).

Dicho todo esto, puedo formular mi tesis: 62 está armada como un calidoscopio. Las primeras treinta páginas presentan al lector una de las posibles rosas del calidoscopio: fragmentos de una historia que se disponen en un diseño a que las obliga el restaurante Polidor, el pedido del comensal gordo, la botella de Sylvaner, el libro de Butor, un día de nochebuena en que Juan decide tomar una copa. Marrast dice: "Juan tendía a verlo todo como en una galería de espejos, y por lo demás ya debía haberse dado cuenta de que Nicole y yo habíamos entrado a formar parte, desde una tarde en una carretera italiana, de ese calidoscopio que él se pasaba la vida queriendo fijar y describir"(p.49). Y más adelante, el mismo Marrast: "También Juan podría estar pensando una cosa así, la rosa del calidoscopio se hubiera fijado graciosamente, con su aburrida simetría inevitable, pero nadie podía ser y quitar a la vez una astillita azul o una cuenta púrpura, si agitaba el tubo y la figura se armaba por su cuenta ya no se podía ser a la vez la mano y la figura" (p. 50).

Lo primero que aparece ante la vista del lector es esa figura en que los cristales de una posible clave y las astillas de una historia se disponen según equidistancias y simetrías intraducibles todavía a ningún sentido. Forman a lo sumo, como ya anticipáramos, un ideograma, el ocular de ese calidoscopio que deja ver una primera imagen. La lectura de 62 podría compararse a una multiplicidad de figuras calidoscópicas que en su dinámica volubilidad y diversidad permiten explicar o "fijar" esa primera rosa como introito u obertura de la novela.

Esa primera figura o rosa inicial invita a entrar en el tubo que es la novela en busca de nuevos diseños que al sobreponerse nos revelarán finalmente una posible clave. Y el texto de 62 está armado como un tubo en el que tres planos espaciales-Londres, Viena y París-forman un prisma de espejos. Los breves capítulos no están numerados. Enumerarlos hubiera sido deslindarlos y de lo que se trata es de borrar lindes, enumerarlos es una forma de aislarlos y esos capítulos están unidos entre sí, se deben los unos a los otros, dependen el uno del otro, se reflejan el uno en el otro, muy a la manera de los espejos de un calidoscopio que funcionan desde su adyacencia y su naturaleza auto- 
reflexiva. Las tres ciudades en las que pivotea el relato participan de ese caracter reflexivo de los personajes y sus acciones. Londres es Londres es Londres, pero para los fines de la novela y el mundo de los personajes, Londres, París y Viena son ciudades que forman la ciudad, la zona, un espacio en que las tres ciudades se aúnan para convertirse en el lugar público que vale como punto de encuentro e interacción de los personajes: "Tell había sido Roma, Lugano, Viña del Mar, Teherán, Londres, Tokío, y por qué no ahora Viena con sus cafés a mables, sus dieciseis Breughel, sus cuartetos de cuerda y su viento de esquinas", (p. 60) dice Juan. El poema intercalado entre el soliloquio de Juan y el tex to del relato subraya esa función-escenario de la ciudad.

Llevando un poco más allá todavía el modelo del cual partimos, podría decirse que la ciudad vale como suelo de los personajes que saltan, de hecho o de derecho, de una a otra ciudad como los trocitos de vidrio del calidoscopio a cada vuelta del tubo. Lo que lo hace girar es la manera como está dispuesta la narración: Londres-Viena-Londres-Viena-Londres, etc. hasta la página 100 en que París se incorpora al movimiento de rotación del tubo. Con cada movimiento del tubo, la rosa primera, críptica y llena de promesas, se abre a su significación, aunque muy lenta e imperceptiblemente.

En Londres está la mayor parte del grupo: Calac, Polanco, Marrast, Nicole, Austin y dos personajes-puntos de apoyo: Feuille Morte y "mi paredro"; la primera es efectivamente una hoja muerta que solamente dice "Bisbis bisbis" en toda la novela y el segundo es un personaje ubicuo que sólo existe como reflejo de algún otro personaje. Vienen a Londres para acompañar a Marrast a conseguir una piedra de hule y volverán a París con la piedra cumplida. En Viena están Juan y Tell. Tell viajará a Londres a unirse al grupo y Juan, a París cuando concluye su trabajo de traductor. En París, finalmente, están Celia y Hélène. Celia se une al grupo en Londres antes del regreso de todo el grupo a París.

Pero hasta llegar al encuentro final de todo el grupo en el tren que los lleva de Arcueil, donde se instala e inaugura la escultura de Marrast, a París, las verdaderas asociaciones y afinidades del grupo han sido ya establecidas como el diseño que reúne un grupo de estrellas en una constelación. Calac y Polanco son dos perfectos cronopios para quienes el humor, la locura y el absurdo constituyen el pan suyo de cada día. Hacia el final el uno le dice al otro: "Vos tenés razón, todo salió muy mal pero no dirán que no nos divertimos"(p. 201). Como el nombre de Calac, estos dos personajes forman un palíndroma: el uno es reflejo o espejo del otro y participan además de relaciones con el resto del grupo. Este rasgo es extensivo a los otros personajes con la variante de que además de la aleación de pareja hay otras afinidades que los reúnen en triángulos: Marrast quiere a Nicole que no quiere a Marrast pero ama a Juan. 
Juan y Tell forman otra pareja en Viena pero Juan no ama a Tell sino a Hélène. Hélène seduce a Celia en París pero Celia se enamora de Austin en Londres. Nótese como en cada caso un personaje está unido a otro pero en realidad se siente unido a un tercero en otra ciudad estableciendo los siguientes triángulos:

Marrast-Nicole-Juan (Londres-Viena)

Juan-Tell-Hélène (Viena-París)

Hélène-Celia-Austin (París-Londres)

A estos triángulos centrales se suman triángulos periféricos: Frau Marta seduce a la chica inglesa, pero la seducción vampirista de Frau Marta la relaciona de inmediato con la condesa Erszebet Báthori como claramente precisa el texto en la página 175. El muchacho que se le muere a Hélène en la sala de operaciones se parece a Juan. Solamente cuando esto último ocurre y se cierra el triángulo paciente-Hélène-Juan, se abre el siguiente Celia-HélèneJuan, no sin que antes actúe como catalizador o maleficio la muñeca fabricada por Monsieur Ochs. También esta muñeca rueda por las paredes del calidoscopio de la novela entrando y afectando varias de sus figuras: Monsieur Ochs que la fabrica, no sin antes esconder un objeto extraño en su estopa, se la regala a Juan que, a su vez, se la regala a Tell que, a su vez, se la regala a Hélène que, a su vez, se la presenta a Celia. La muñeca se rompe y descubre su objeto ominoso después de la violación de Celia por Hélène. La muñeca está también ligada a Juan y al muchacho-paciente que se parece a Juan. El paciente es para Hélène un primer substituto o transferencia de Juan y se le muere; la muñeca, aunque indeseable, un segundo substituto ("Debiste venir tú en vez de mandarme la muñeca, pensó Hélène", p. 170) y se rompe. Además, la muñeca representa también al paciente muerto ("Ya lo habrán abierto como quien abre una muñeca para ver lo que tiene adentro", [p. 168]). El motivo de la muñeca queda resumido en las palabras de Hélène: “... Alguien habría subido un lienzo blanco hasta el mentón del muchacho muerto, y entonces la muñeca de Tell (o más bien de Juan) era Celia que era el muchacho muerto y yo decidía y cumplía las tres ceremonias", (pp. 166-167).

Tres ceremonias y tres seducciones: Nicole seduce a Austin, Frau Marta seduce a la chica inglesa, Hélène seduce a Celia. En este mismo orden y casi sin intermitencias. Los seducidos del grupo-Celia y Austin - se unen y redimen por el amor ( $\mathrm{y}$ la venganza); las seductoras del grupo se pierden: Hélène asesinada por Austin, Nicole arrastrada por los embrujos de Frau Marta en ese mismo pontón que aparece al principio de la novela y reaparece hacia el final con "Frau Marta acercándose por detrás a Nicole, tomandola cariñosamente del brazo, hablándole al oído..." (p. 267).

También el motivo del basilisco hace eco en tres aristas de la novela. Aparece en la Basilisken Haus en Viena como "un basilisco en altorrelieve 
lleno de patas y espinas y todas las cosas que suelen tener los basiliscos cuando caen en las manos de los artistas"; el basilisco "que en otros tiempos había llevado M. Ochs en un anillo de plata, un basilisco verde echándose inexplicablemente fuego en la cola"(p. 96); y el basilisco de Hélène: "un clip que Hélène se ponía pocas veces porque el basilisco según ella era sensible a los colores" (p. 96). El basilisco desata una cadena de asociaciones: casa del basilisco, monsieur Ochs, "muñecas torturadas y desgarradas", Blutgasse, condesa, Hélène, y "un territorio donde vagamente latía el miedo"(p. 96).

Hay finalmente ecos más asordinados: la mención de una novela de John Le Carré, seguramente Carmilla de tema vampiresco y en la que el vampiro es una mujer lesbiana. La referencia a Diana y Acteon en relación a Hélène y Juan. Diana la cazadora virgen, rodeada de vírgenes ninfas que la sirven y protegen, celosa hasta la crueldad de su castidad, se toca con una Hélène nunca poseída, para quien la atracción hacia Celia es su virginidad y que siente que en "alguna parte de su ser hay perros que esperan"(p. 238) y que podrían destrozar a Juan a quien su paredro llamó una vez Acteón.

No hay ningún personaje, o situación o elemento narrativo que no suscite un eco, que no provoque una imagen de espejo, que no encuentre una substitución o transferencia. El tiempo de la novela es tan viscoso como su espacio: el primer soliloquio de Juan pudo haber tenido lugar antes o después de los hechos novelados; lo que ocurre en el Hotel Rey de Hungría en Viena, cerca de la Blutgasse, ya ocurrió hace varios siglos en la Viena de Klara Báthory. El último encuentro de Hélène y Juan, hacia el final de la novela, en el que finalmente se quieren y reconcilian, tiene lugar inmediatamente después que todo el grupo se desbanda y en el tren quedan solamente Feuille Morte, Hélène y Juan. Pero al final del encuentro regresamos a la escena del tren que la precede y se repite el breve diálogo primero, como si el erótico encủentro entre Juan y Hélène no hubiera ocurrido o, tal vez, hubiera ocurrido en un tiempo fuera del tiempo, o en un tiempo que pudo ser anterior o posterior a la escena y diálogo del tren porque lo que importa no es cuándo ocurrió sino que tuvo lugar o que debía o pudo haber tenido lugar. En la página 190 Tell dice "mañana le enviaré la muñeca a Hélène", pero varios de los capítulos anteriores tratan de la muñeca ya recibida por Hélène. La cronología del tiempo está trastrocada de manera que el presente puede ser un eco del futuro o viceversa, el pasado un eco del presente, o tal vez el pasado está donde debería estar el futuro. Juan resume este esfuerzo por acabar con la tiranía de un tiempo ordenado: "Mostrar cómo una vez más el antes y el después se le destrozaban de las manos, dejándole una fina inútil lluvia de polillas muertas" (p. 27). Y Hélène define la noción de tiempo de la novela: "En las situaciones últimas, el antes y el después se tocan y son uno solo"(p. 144). 
También la narración como enunciado participa de una maleabilidad semejante. El método está formulado por el propio Juan cuando dice: "Le gustaba narrar las historias con un cierto desorden artístico mientras que Tell parecía ansiosa por llegar de una vez al desenlace" (p. 97). Desorden de calid oscopio porque, como el arte, sus espejos ordenan el azar en estructuras o formas. Casi todos los personajes asumen en un momento determinado la narración. Hay, pues, tantos narradores como personajes. Además, la narración pasa de la tercera persona a la primera sin transición alguna, en el mismo párrafo. En la página 127 la narración en tercera persona cede la narración a una primera persona (Tell) apenas después de una coma. En la página 164 el relato en tercera persona pasa a la primera de Hélène después de un punto. Según las necesidades del relato, la narración se da en primera, tercera y segunda persona. En la página 190 la narración comienza en tercera desde el punto de vista de Tell; después de un punto y coma a mitad del párrafo Tell misma asume la narración en primera persona; y hacia el final, Tell, otra vez, retoma la narración en segunda persona. Hay, finalmente, ejemplos de narración simultánea: el mismo narrador presenta dos narraciones diferentes dentro del mismo párrafo, como en la página 165 en la que Hélène narra su encuentro con Celia y, a la vez, su itinerario por la ciudad y sus esfuerzos por tomar un tranvía.

Desde la escena inicial en el restaurante Polidor hasta el bisbiseo final que la cierra, Cortázar ha arma do su novela como un calidoscopio en el que el triple juego de espejos determina en cada personaje su reflejo, en cada situación una imagen revertida, en el manejo del tiempo inversiones que cancelan el tiempo lineal y en el método narrativo una multiplicidad de narradores que cambian señales, se desdoblan, duplican, triplican y buscan, denodadamente, "otro orden" (p. 177), "otra manera de entender" (p. 178). Esa combinatoria de rosas y figuras en constante movimiento, ese juego de imágenes telescópicamente dispuestas en un tubo y glosándose infinitamente, es la respuesta novelística de Cortázar al programa de Morelli: una clave todavía no formulada, los primeros parpadeos de un tercer ojo.Poner a prueba esa clave, ver según esa óptica nueva es tarea del lector. Lo que la novela provee es apenas, y es mucho, una galería de espejos, un reticulado no tejido todavía, un collar de imágenes pero sin hebra. Corresponde al lector encontrar esa hebra, o como dice Juan, "una de la hebras que hubiera querido atar a las otras hebras para alcanzar por fin una comprensión, algo que acaso hubiera tenido imagen y nombre" (p. 179).

Un calidoscopio convierte, gracias a su elemental maquinaria de espejos, el caos del azar en un orden, en formas que buscan el placer estético y que otorgan algún sentido al caos. No otra es la función del arte. El "calidoscopio" de Cortázar difiere de la novela tradicional por su armazón. Si, como 
anunciaba Morelli, lo que esa novela busca es una nueva clave que reemplace las viejas, se comprende que su armado responda también a una arquitectura nueva, a una forma más afín a sus propósitos. Cortázar advertía, en el breve prefacio a su novela, que el subtítulo-_"modelo para armar"-alude no tanto a las diferentes partes del relato, a su armado composicional, que busca "liberar toda fijeza causal", como al nivel "del sentido donde la apertura a una combinatoria es más insistente e imperiosa". Lo que Cortázar dice es que su novela-calidoscopio está ya cuidadosamente armada y que corresponde al lector otorgar algún sentido a esa sucesión de rosas en constante movimiento. Pero en literatura como en arte el sentido no es nunca independiente de las formas a través de las cuales se expresa. Más aun: esas formas constituyen el modo de hablar de una obra. El mensaje más poderoso del arte realista está transmitido desde ese orden cronológico y causal al cual está sujeto el material narrativo, al igual que la obra surrealista habla desde ese aparente desorden que no es sino la búsqueda de un nuevo orden, la formulación de un código diferente. Victor Shklovsky definía al escritor como "un organizador de materiales que forma un artefacto colocando una pieza junto a las demás". Por eso para Shklovsky el ser de la literatura residía en esa forma o estructura y la tarea del crítico consistía en el estudio de esa forma con que el escritor disponía u organizaba sus materiales. Encontró obras literarias en que el material se organizaba como una construcción de escalinata (stupenchatost), otras, como una estructura de cestería (pletenka), algunas como un juego de ajedrez, o una urdimbre, o un marco dentro de otro, o una construcción laberíntica. Esa organización no es nunca arbitraria: responde a una cosmovisión, o visión o entrevisión que intenta formularse por debajo del texto. Desde su organización calidoscópica, ¿qué propone 62 ? Una sucesión de imágenes que por su condición cinética se niegan a una verdad congelada en axiomas y que buscan, en cambio, no "el hombre que es sino que proyecta ser". Esas rosas que se forman en la novela, y que constantemente se truecan en otras, definen una verdadera poética del movimiento. La rosa final no está en la novela como no está en el calid oscopio. Tampoco es seguro que emerja de su mera yuxtaposición o combinación. No hay rosa final que corresponda a una taxonomía como es imposible clasificar las rosas de un calidoscopio. Pero de la superposición de esas imágenes es posible si no precisar al menos sentir la presencia de una realidad cuyo comentario poético es 62 , muy a la manera como "nuestro llamado conocimiento es", según Nietzsche, "un comentario más o menos fantástico de un texto desconocido, tal vez inconocible pero que es posible sentir". Desde el movimiento, esas rosas "quieren decirnos algo, o algo dijeron, o están por decir algo; y esta inminencia de una revelación, que no se produce, es, quizá, el hecho estético"?

7 Jorge Luis Borges, Otras inquisiciones (Buenos Aires: Emecé, 1960), p. 12. 
